\title{
An Immunohistochemical Study of N-Methyl-D- Aspartate Receptors in Human Cerebellum and Hippocampus
}

\author{
Euphrosyni S. Koutsouraki*, John J. Anastasiades, Stavros J. Baloyannis \\ $1^{\text {st }}$ Department of Neurology, Aristotle University, AHEPA Hospital St. Kyriakidi 1, 54626, Thessaloniki, Greece \\ *Corresponding author: efrosink@gmail.com
}

Received January 03, 2012; Revised April 02, 2013; Accepted April 06, 2013

\begin{abstract}
The aim of our investigation was to demonstrate the wide distribution of glutamate N-methyl-Daspartate receptors (NMDA R), particularly the not-widely investigated 2A and 2B subunits, in the human adult cerebellum and hippocampus. Specimens of human hippocampus and cerebellum were obtained at the time of autopsy from two male individuals, aged 24 and 48 years, with no obvious brain injury. The brains were immunostained using anti-human rabbit polyclonal NR antibodies (NMDA R 2A\&B, AB1548 (Chemicon), NMDA receptors anti- human Poly HRP IHC (Detection kit) and counterstained with Mayer's hematoxylin. The present immunohistochemical research of human adult cerebellum and hippocampus demonstrates that the majority of neurons in the dentate gyrus, the large pyramidal neurons of the hippocampus, the granular cells of the cerebellum as well as the main cerebellar neuron, namely Purkinje cell, stained deeply by the monoclonal antibody, suggesting that the majority of the neuronal network in cerebellum and hippocampus uses as neurotransmitter the excitatory aminoacids on the system of NMDA receptors. Our findings, demonstrating that the majority of cells were stained by the monoclonal antibody, emphasize the importance of the excitatory system of the glutamate and the examined receptors $2 \mathrm{~A} \& \mathrm{~B}$, in the human cerebellum and hippocampus in adults, underlying the important role that this system may play in memory function and cognition, and at the same time the crucial role of the cerebellum in higher cognitive functions, in part due to the wide distribution of NMDA R.
\end{abstract}

Keywords: human hippocampus, human cerebellum, immunohistochemical study, glutamate receptors, $N$-methylD-aspartate receptors

\section{Introduction}

Neuronal plasticity associated with learning, memory and development is controlled, in part, by the fast-acting subunit composition of N-methyl-D-aspartate (NMDA) subclass of glutamate receptor. Moreover, NMDA receptors also play a pivotal role in the pathways culminating in neuronal death in a variety of pathological conditions $[1,2,3]$.

$\mathrm{N}$-methyl-D-aspartate (NMDA) receptors are a class of ionotropic glutamate receptors. NMDA receptor channel has been shown to be involved in long-term potentiation, an activity-dependent increase in the efficiency of synaptic transmission thought to underlie certain kinds of memory and learning. NMDA receptor channels are heteromers composed of three different subunits: NR1 (GRIN1), NR2 (GRIN2A, GRIN2B, GRIN2C, or GRIN2D) and NR3 (GRIN3A or GRIN3B). The NR2 subunit acts as the agonist binding site for glutamate. This receptor is the predominant excitatory neurotransmitter receptor in the mammalian brain.

Several studies demonstrate the extensive distribution of glutamate N-methyl-D-aspartete (NMDA) receptors in human hippocampus suggesting the crucial role of the ionotrophic glutamate receptors in the mechanisms of memory and learning though it is not yet clear their distribution in the human cerebellum and their contribution in the crucial role of the cerebellum in memory and cognition $[5,6,7]$.

Although the NR1 subunit is abundantly expressed by Purkinje cells throughout adulthood [8-15], the expression of NR2 in the adult remains unclear: some authors found signal for NR2-A mRNA in rat and human Purkinje cells $[10,16]$, whereas others detected no messengers for NR2 $[9,13]$. Similarly, low immunoreactivity for NR2-A/B proteins was detected in young rats [17] and adult mice [18], whereas Thompson et al.[19] found clear NR2-B labeling in Purkinje cells from adult rats and mice, as well as NR2-A labeling in mice only and NR2 A\&B in adult mice [20].

NMDA-Rs increase the depolarization induced by the complex spike and prolong its duration. These effects are expected to favor calcium entry in the dendrites as well as their propagation. Thus, NMDA-Rs are likely to be players in the game of mature Purkinje cells plasticity [21,22].

\section{Materials and Methods}


Specimens of human hippocampus and cerebellum were obtained at the time of autopsy from two male individuals, aged 24 and 48 years, without known neurological or psychiatric history, who died during a car accident without demonstrating obvious brain injury. We used paraffin-embedded specimens and two antibodies for immunohistochemical research: anti-human rabbit polyclonal NMDA $\mathrm{R} 2 \mathrm{~A} \& \mathrm{~B}$ as primary antigen and NMDA receptors anti- human Poly HRP IHC (Detection kit) as secondary antigen. The specimens fixed in $10 \%$ formalin were sectioned at $5-7 \mu \mathrm{m}$ thickness using vibrotome, mounted on poly-L-lysine-coated glass slides, and deparaffinized with xylene and a graduated series of ethanol solutions. Subsequently, the sections underwent antigen retrieval via microwave treatment $\left(60^{\circ} \mathrm{C}, 60 \mathrm{~min}.\right)$ and subsequent blocking of the endogenous peroxidase in $3 \%$ hydrogen peroxide for 7.5 minutes at room temperature. They were then rinsed five times with phosphate-buffered saline TBST, soaking afterwards in Peroxidase Blocking Solution for 5min, rinsed three times with TBST and then the sections were incubated at room temperature for $10 \mathrm{~min}$. with anti-human rabbit primary polyclonal antibodies against NMDAR-2 A \& B (Chemicon, Temecula, CA, USA, cat. No. AB1548). Afterwards, the tissue sections were rinsed three times with wash buffer TBST, incubated with secondary antibodies anti- human Poly HRP IHC (Chemicon) for 30min., then rinsed three times with TBST, incubated with DAB Chromogen-Buffer for 20-30min., then rinsed five times with TBST, counterstained with hematoxylin for 1 to $2 \mathrm{~min}$. and dehydrated with a graduated series of ethanol solutions.

\section{Results And Discussion}

The monoclonal antibody has infiltrated all the Purkinje cells of the cerebellar cortex staining dark the soma as well as the apical dendrites of the Purkinje cells. Rare stellate cells have also been stained by the monoclonal antibody and some profiles of basket cells were also visualized stained dark. The majority of the cells of the granular layer have been stained by the monoclonal antibody, a fact which supports the wide distribution of the NMDA receptors (NMDA R) in the cerebellar cortex in human adults (young and middle-aged). In some parts of the cerebellum the monoclonal antibody infiltrates mostly the basal part of the Purkinje cell. It's important to mention that rough congregates of the granular cells of the cerebellum, stained by the monoclonal antibody, are located underneath the Purkinje cell layer in round or rosette- like arrangements. The molecular layer of the cerebellum in each of the cerebellar hemisphere demonstrates the aggregation of the stellate cells stained by the monoclonal antibody sometimes in columnar arrangement. The astrocytes were not stained and remained therefore invisible in the cortical background. (Figure 1)

The monoclonal antibody infiltrates deeply also the dentate gyrus of the hippocampus. This gyrus is composed of round small cells in compact arrangement, the majority of them been stained by the monoclonal antibody (Figure 2). The pyramidal neurons of the hippocampus are clearly visualized, the majority of them been stained by the monoclonal antibody (Figure 3).

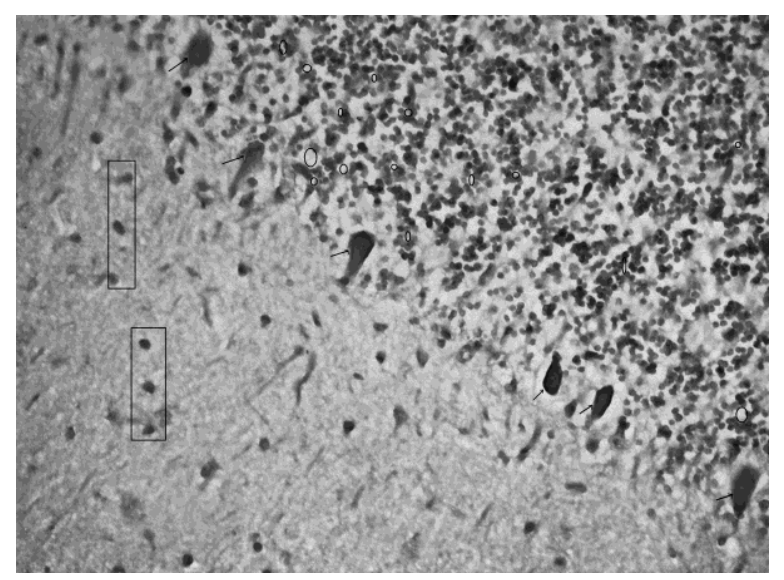

Figure 1. Cerebellar cortex

Purkinje cells, highly immunostained with NMDA R 2A \&2B,

demonstrating dark stained soma and apical dendrites, are marked with

Rough congregates of the granular cells of the cerebellum, stained by the monoclonal antibody, are located underneath the Purkinje cell layer in round or rosette- like arrangements. Rosette structures of granular cells are marked with $\longrightarrow$

The molecular layer of the cerebellum demonstrates the aggregation of the stellate cells stained by the monoclonal antibody, sometimes in columnar arrangement, that are marked with

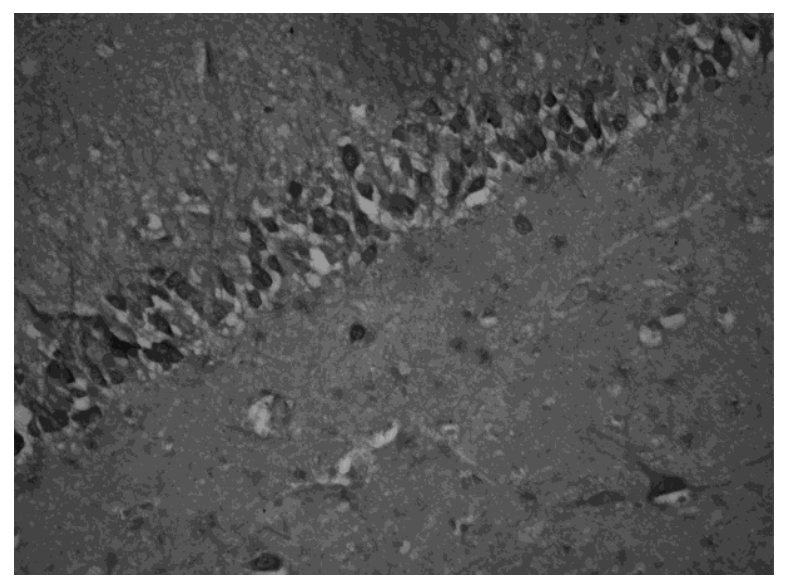

Figure 2. Dentate gyrus of the hippocampus

This gyrus is composed of round small cells in compact arrangement, the majority of them been stained by the monoclonal antibody

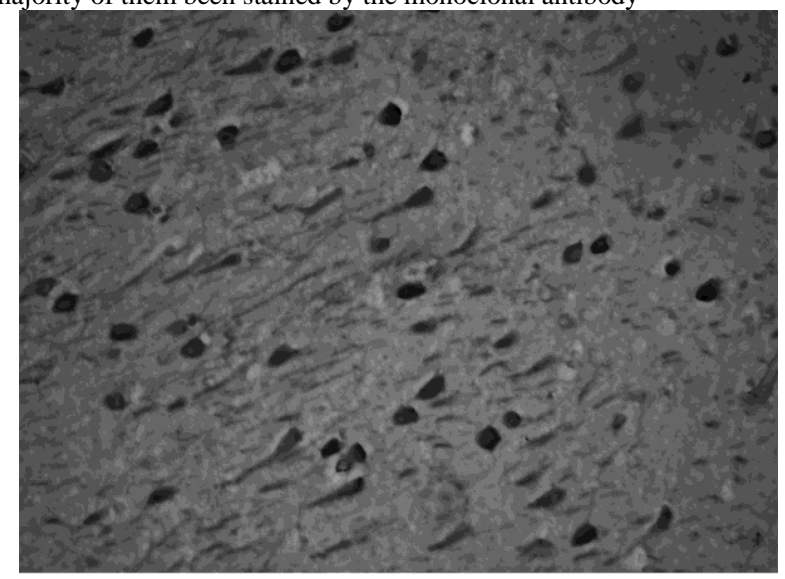

Figure 3. Pyramidal neurons of the hippocampus

They are clearly visualized and deeply stained by the monoclonal antibody 
The present immunohistochemical research of human adult cerebellum and hippocampus, demonstrates that the majority of neurons in the dentate gyrus, the large pyramidal neurons of the hippocampus, the granular cells of the cerebellum as well as the main cerebellar neuron, namely Purkinje cell, stained deeply by the monoclonal antibody, uses as neurotransmitter the excitatory aminoacids, on the system of NMDA R 2A\&B. Since it isn't well known the distribution of NMDA R, especially the subtypes $2 \mathrm{~A} \& \mathrm{~B}$, in human hippocampus and cerebellum in adults, our findings emphasize the importance of the excitatory system of the glutamate in these areas, underlying the important role that this system may play in memory function and cognition and at the same time the crucial role of the cerebellum in higher cognitive functions, in part due to the wide distribution of NMDA R.

\section{References}

[1] Conti F, Barbaresi P, Melone M, Ducati A., "Neuronal and glial localization of NR1 and NR2A/B subunits of the NMDA receptor in the human cerebral cortex," Cerebral cortex, 9. 110-20. 1999.

[2] Dingledine R, Borges K, Bowie D, Traynelis SF., "The glutamate receptor ion channels", Pharmacol, Rev 51:7-62. 1999.

[3] Cull-Candy S, Brickley S, Farrant M. "NMDA receptor subunits: diversity, development and disease," Curr Opin Neurobiol, 11. 327-335. 2001

[4] Mori H, Mishina M., "Roles of diverse glutamate receptors inbrain functions elucidated by subunit-specific and region-specific gene targeting, ” Life Sci, 74. 329-336. 2003.

[5] Mathern GW, Leite JP, Pretorius JK, Quinn B, Peacock WJ, Babb TL., "Aberrant hippocampal mossy fiber sprouting correlates with greater NMDAR2 receptor staining", Neuroreport, 7. 1029-35. 1996.

[6] Sisodiya SM, Heffernan J, Harrison PJ, Squier MV, Thom M., "Sulcogyral variation in NMDA receptor 2A/B subunit immunoreactivity in human brain", Neuroreport, 11.2601-6. 2000.

[7] Moriyoshi K, Masu M, Ishii T, Shigemoto R, Mizumo N, Nakanishi S. "Molecular cloning and characterization of the rat NMDA receptor," Nature, 354:31-37.1991.

[8] Monyer H, Sprengel R, Schoepfer R, et al. "Heteromeric NMDA receptors:molecular and functional distinction of subtypes," Science, 256. 1217-1221. 1992.
[9] Monyer H, Burnashev N, Laurie DJ Sakmann B, Seeburg PH. "Developmental and regional expression in the rat brain and functional properties of four NMDA receptors," Neuron, 12. 529540. 1994.

[10] Akazawa C, Shigemoto R, Bessho Y, Nakanishi S, Mizuno N. "Differential expression of five N-methyl-D-aspartate receptor subunit mRNAs in the cerebellum of developing and adult rats," $J$ Comp Neurol, 347. 150-160. 1994.

[11] Laurie DJ, Seeburg PH. "Regional and developmental heterogeneity in splicing of the rat brain NMDAR1 mRNA," $J$ Neurosci, 14.3180-3194. 1994.

[12] Petralia R, Yokotani N, Wenthold R., "Light and electron microscope distribution of the NMDA receptor subunit NMDAR1 in the rat nervous system using a selective anti-peptide antibody," J Neurosci, 14. 667-696. 1994a.

[13] Watanabe M, Mishina M, Inoue Y. "Distinct spatiotemporal expressions of five NMDA receptor channel subunit mRNAs in the cerebellum," J Comp Neurol, 343.513-519. 1994.

[14] Nakagawa S, Watanabe M, Inoue Y. "Altered gene expression of the N-methyl-D-aspartate receptor channel subunits in Purkinje cells of the staggerer mutant mouse," Eur J Neurosci, 8. 26442651. 1996

[15] Hafidi A, Hillman DE. "Distribution of glutamate receptors GluR $2 / 3$ and NR1 in the developing rat cerebellum," Neuroscience, 81:427-436.1997.

[16] Scherzer CR, Landwehrmeyer GB, Kerner JA, et al., "Cellular distribution of NMDA glutamate receptor subunit mRNAs in the human cerebellum," Neurobiol Dis, 4.35-46. 1997.

[17] Petralia RS, Wang YX, Wenthold RJ. "The NMDA receptor subunits NR2A and NR2B show histological and ultrastructural localization patterns similar to those of NR1," J Neurosci, 14. 6102-6120. 1994b.

[18] Yamada K, Fukaya M, Shimizu H, Sakimura K, Watanabe M., "NMDA receptor subunits GluRepsilon1, GluRepsilon3 and GluRzeta1 are enriched at the mossy fibre-granule cell synapse in the adult mouse cerebellum," Eur J Neurosci, 13. 2025-2036. 2001.

[19] Thompson CL, Drewery DL, Atkins HD, Stephenson FA, Chazot PL. "Immunohistochemical localization of N-methyl-D-aspartate receptor NR1, NR2A, NR2B and NR2C/D subunits in the adult mammalian cerebellum," Neurosci Lett, 283. 85-88. 2000.

[20] Piochon C, Irinopoulou T, Brusciano D, Bailly Y, Mariani J, Levenes C. "NMDA receptor contribution to the climbing fiber response in the adult mouse Purkinje cell," The Journal of neuroscience, 27. 10797-809. 2007.

[21] Llinas R, Sasaki K. "The functional organization of the olivocerebellar system as examined by multiple Purkinje cell recordings," Eur J Neurosci, 1. 587-602. 1989.

[22] Khaliq ZM, Raman IM. "Axonal propagation of simple and complex spikes in cerebellar Purkinje neurons," J Neurosci, 25. 454-463. 2005. 